\title{
П.А. Крюков
}

\section{ПОНЯТИЕ ФИНАНСОВЫХ ИНВЕСТИЦИЙ НА МЕЖДУНАРОДНОМ ВАЛЮТНОМ РЫНКЕ}

\begin{abstract}
Выполнена систематизации подходов различных ученых к толкованию понятия «финансовые инвестиции». Выявлена проблема неоднозначного толкования инвестиций на международном валютном рынке. Предложено уточненное определение, отличающееся тем, что толкует инвестиции в иироком и узком смыслах, относя к финансовым инвестициям вложения финансовых ресурсов с различными целями, в том числе осуществляемые посредством спекулятивных операций. Выделены сущностные признаки этого понятия, позволяющие отличить финансовые инвестиции от реальHblx.

Ключевые слова: финансовые инвестиции, спекулятивные операции, валютный рынок, финансовый актив, инструмент..
\end{abstract}

В настоящее время в экономической литературе понятие «финансовые инвестиции» не имеет однозначного толкования для валютного рынка. Нет единого мнения, являются ли инвестиционными спекулятивные операции, особенно на внебиржевом валютном рынке, и являются ли все торговые операции, выполняемые с различными целями, инвестиционными.

Высокий объем спекулятивных операций (более 80\%) [1], осуществляемых на валютном рынке, обосновывает необходимость уточнения этого понятия в теории инвестиций с практической точки зрения.

Цель статьи - проанализировать различные подходы к толкованию финансовых инвестиций; выявить сущностные признаки, позволяющие отличить финансовые инвестиции от реальных; предложить уточненную трактовку применительно к международному валютному рынку.

Рассмотрим различные толкования понятия «финансовые инвестиции».

По мнению В.Н. Салина [2], с одной стороны, инвестиции на валютном рынке - это крупные долгосрочные вложения в различные валюты институциональными участниками рынка, перевод национальной валюты в иностранную и вложение средств в иностранные активы, с другой - это использование денежных ресурсов для личной торговли или для передачи в доверительное управление профессиональному участнику рынка (брокеру) с целью извлечения прибыли.

Большинство подходов делит инвестиции с позиции объекта вложения капитала на две группы: финансовые (вложения в финансовые активы) и реальные (вложения в нефинансовые активы).

Как правило, реальные инвестиции трактуются как «вложения капитала в материальные (основные и оборотные средства) и нематериальные активы с определенной целью на определенный срок» [3. С. 19], а под финансовыми инвестициями понимают портфельные инвестиции на фондовом рынке [4, 5]. Однако портфельные инвестиции присутствуют и на валютном рынке (валютные порт- 
фели), причем они довольно часто не преследуют долгосрочных целей и носят спекулятивный характер.

Различают прямые инвестиции - долгосрочные вложения, при осуществлении которых инвестор преследует долгосрочные цели. Такие операции не носят спекулятивного характера.

Так, в работе И.С. Межова и С.И. Межова [3. С. 20] финансовые инвестиции делятся «на спекулятивные (спекулятивные операции) и долгосрочные (кредитно-депозитные операции на рынке капиталов)». Финансовые инвестищии определяются как «вложения капитала в различные финансовые инструменты (активы)», в том числе в валюту, депозиты, ценные бумаги, акции и пр. [3. С. 377]. Инвестиционная деятельность определяется как «вложение инвестиций и осуществление практических действий в цзелях получения прибыли и (или) достижения иного полезного эффекта» [3. С. 368]. Таким образом, И.С. Межов и С.И. Межов относят к инвестиционным операциям на финансовых рынках только спекулятивные и кредитно-депозитные операции на рынке капиталов, что, на наш взгляд, не совсем верно.

Б.А. Райзберг [4. С. 124] определяет инвестиции как «долгосрочные вложения капитала в собственной стране или за рубежом ... финансовые (портфельные), вкладываемые в акции, облигации и др. ценные бумаги», и считает, что «инвестор - юридическое или физическое лицо, осуществляющее инвестиции, вкладывающее собственные, заемные или привлеченные средства в инвестиционные проекты» [4. С. 125].

Ю.А. Корчагин [6. С. 15] определяет инвестиции как «долгосрочные вложения финансовых или экономических ресурсов с щелью получения доходов или иных благ в будущем».

Л.А. Чалдаева [7. С. 412] приводит следующее определение инвестиций в финансовые активы - «вложение капитала в различные финансовые инструменты, а также в активы др. предприятий ... в целях получения прибыли и достижения положительного эффекта». Инвестиционную деятельность определяет как «процесс вложения средств в инвестиционные проекты и совокуnность практических действий по их реализации» [7. С. 512], а инвестиционный проект определяется через цель и комплекс действий, направленных на достижение цели.

М.В. Чиненов [8. С. 8] рассматривает сущность инвестиций с различных сторон. В общем случае определяет инвестиции как «вложение капитала в какоелибо дело путем приобретения ценных бумаг или непосредственно предприятия (прямые инвестиции) в целях получения дополнительной прибыли или воздействия на дела предприятия». Однако применительно к рынку ценных бумаг он определяет финансовые инвестиции как «операщии с ценными бумагами - вложения в финансовые активы (инструменты), т.е. в акции, облигации и др. ценные бумаги ... а также объекты тезаврации, банковские депозиты». По нашему мнению, такая трактовка не совсем точная, надо различать «операции» и «вложения», осуществляемые путем совершения операций.

В работе М.В. Довбенко и Ю.И. Осик «Современные экономические теории в трудах нобелиантов» [8] в прил. 2 приводится следующее определение: «Инвестиции (капиталовложения) - совокупность товаров, приобретенных юридическими или физическими лицами для увеличения накопленного капитала». Из 
определения следует, что инвестиции - это результат совершенной операции «приобретения» с целью увеличения исходного капитала.

По мнению М.В. Чиненова, инвестиционная деятельность - это «вложение инвестиций, или инвестирование, и совокупность практических действий по реализации инвестиций в целях получения доходов в будущем и достижении иного полезного эффекта» [8. С. 336].

М.В. Чиненов также указывает на финансовые инвестиции как экономическую категорию и как прочесс - «совокупное движение инвестиций различных форм и уровней» [8. С. 9], который реализуется с помощью «механизма инвестиционного рынка». Финансовый рынок рассматривается как часть инвестиционного рынка, который «представляет собой систему торговли различнылии фuнансовыми инструментами (обязательствами). Товаром выступают собственно наличные деньги (включая валюту), банковские кредиты и ценные бумаги» [8. C. 13]. К финансовым рынкам М.В. Чиненов относит и валютный рынок. По мнению М.В. Чиненова [8. С. 110], доходность и риск- основные характеристики финансовых инвестиций. Автор статьи в целом согласен с мнением, но считает, что к основным характеристикам (признакам) надо отнести «цель» и «финансовый актив» [10]. Чиненов указывает, что изель инвестищий «состоит в стремлении получить требуемый уровень ожидаемой доходности при более низком уровне ожидаемого риска» за счет «тщательного подбора финансовых инструментов» [8. С. 110], речь идет о портфельных инвестициях на фондовом рынке. Однако на валютном рынке цели участников рынка различны.

А.Г. Грязнова и др. [11. С. 1032] определяют финансовые инструменты как «финансовые активы/пассивы, которые можно покупать и продавать на рынке и посредством которых осуществляется распределение и перераспределение созданного капитала. Финансовый инструмент представляет собой юридический документ - договор, отражающий договорные взаимоотношения или предоставляющий определенные права». Это справедливо для валютного рынка.

И.А. Бланк [12. С. 30-31] к основным «сущностным характеристикам инвестиций предприятий относит: связь со сферой экономических отношений», в частности, рассматривает инвестиции «как объект рыночных отношений... инвестиционные ресурсы как объект купли-продажи на инвестиционном рынке, который характеризуется спросом, предложением и ценой, а также совокупностью определенных субъектов рыночных отношений». К инвестиционным рынкам он также относит валютный рынок [12. С. 274], а торговые операции называет «инвестиционными» [12. С. 276]. Операщии на инвестиционном рынке понимаются как «реализация отдельных управленческих решений, связанных с формированием и использованием инвестиционных ресурсов... обеспечиваемая заключением необходимых сделок с партнерами по инвестиционным отношениям» [12. С. 322].

Также И.А. Бланк [13. С. 14] «к формам финансового инвестирования» предприятий относит «вложения капитала в уставные фонды совместных предприятий, в доходные виды фондовых инструментов, в доходные виды денежных инструментов». 
Анализ трактовок понятий «финансовые инвестиции», «инвестиционная деятельность (инвестирование)» различных авторов позволяет выделить три подхода к определению понятия «финансовые инвестиции»:

1) финансовые инвестиции - это вложения собственных, заемных и привлеченных денежных средств в финансовые инструменты (финансовые активы, обязательства) с определенной целью - «получить требуемый уровень ожидаемой доходности при более низком уровне ожидаемого риска» или «достижение иного полезного эффекта» $[3,4,6,7,8]$;

2) финансовые инвестиции - это вложения путем совершения операций купли/продажи финансовых инструментов на инвестиционном рынке, частью которого является валютный рынок [8, 12];

3) финансовые инвестиции как экономическая категория и как процесс «совокупное движение инвестиций различных форм и уровней» [8. С. 9], который реализуется с помощью механизма инвестиционного рынка.

Все подходы, по нашему мнению, делают акцент на конкретном сущностный аспекте - это вложения с определенной целью, форма вложения - через операции купли/продажи финансовых инструментов, реализация инвестиций осуществляется посредством механизма инвестиционного рынка. Определение инвестиционных операций как операций по реализации отдельных управленческих решений, связанных с формированием и использованием инвестиционных ресурсов - объектов купли/продажи [12], обосновывает необходимость управления финансовыми отношениями, возникающими в процессе инвестирования между участниками рынка.

И.А. Бланк [12. С. 17] называет десять сущностных признаков финансовых инвестиций предприятий. На наш взгляд, шесть из них наиболее полно представлены для финансовых инвестиций на валютном рынке: (1) ликвидность актива, (2) наличие риска, (3) источник прибыли (дохода), (4) объект рыночных отношений (объект купли/продажи), (5) объект управления, (6) активная форма вовлечения капитала (сбережений) в экономический процесс.

Ликвидность (1) валютного рынка и обращающихся на нем активов подтверждается наличием постоянного спроса и предложения, позволяющего реализовать актив по рыночной цене с возможностью быстрой конверсии в денежные средства, большой объем операций и небольшой спрэд.

Наличие высокого риска (2), возможность получения высокого дохода (3) характерны для спекулятивных операций на валютном рынке.

Финансовые инвестиции - вложения, осуществляемые путем совершения операций купли/продажи финансовых инструментов (4), имеющих спрос, цену, предложение, характеризуются совокупностью рыночных (экономических) отношений, возникающих между субъектами рынка по поводу перераспределения инвестиционных (финансовых) ресурсов его участников. Цена финансового инструмента формируется под влиянием спроса и предложения на рынке с учетом инвестиционной привлекательности.

Высокий риск и высокая потенциальная доходность операций на валютном рынке обусловливают необходимость управления процессом инвестирования финансовыми отношениями между участниками рынка, поэтому финансовые инвестиции - объект управления (5). 
Накопленный капитал (сбережения) участников валютного рынка является инвестиционным ресурсом, который посредством инвестирования вовлекается в экономический процесс (6). Купля/продажа - активная форма вложения капитала. Остальные четыре сущностных признака («объект временного предпочтения, объект собственности и распоряжения, альтернативная возможность вложения капитала в любые объекты, возможность использования накопленного капитала во всех альтернативных его формах») также справедливы для финансовых инвестиций, но не являются сущностными, на наш взгляд.

К указанным признакам, отличающим реальные и финансовые инвестиции, по нашему мнению, надо добавить ранее установленные сущностные признаки торговой операции [10] - цель и базисный актив, лежащий в основе финансового инструмента, а также форму и объект инвестирования, необходимость управления процессом инвестирования (таблица).

А.П. Иванов [14. С. 46] указывает две обязательные характеристики для квалификации операций с финансовыми инструментами как финансовых инвестиций: а) «в основе операции должны лежать финансовые активы и обязательства; б) операция должна иметь форму договора (контракта)».

Таковыми являются операции купли/продажи финансовых инструментов на наличном и срочном рынках, осуществляемые с различными целями, в том числе с целью спекулящии (валютные пары, опционы, фьючерсы, форварды - расчетные, без поставки актива), хеджсрования (опционы, фьючерсы, форварды, свопы - с поставкой актива и без поставки в совокупности со сделкой на наличном рынке), кредитно-депозитные операции (свопы иностранной валюты, процентные свопы).

И.А. Бланк [13. С. 96] различает инвестиционный эффект по целям инвестирования: (1) социальные, внеэкономические цели, не предполагающие получение инвестиционной прибыли, и (2) экономические цели, предполагающие получение дохода от вложений. В этом смысле приобретение иностранной валюты на валютном рынке (конверсионные операции) для осуществления внешнеэкономической деятельности к инвестициям не относит, так как они не предполагают получение дохода. Однако покупку, накопление ликвидного актива в инвестиционных целях в будущем относит к инвестициям и продажу выручки от экспорта продукции также относит к инвестиционным операциям [12. С. 265].

На наш взгляд, участники рынка инвестируют собственные, заемные и привлеченные денежные средства в финансовые инструменты валютного рынка с целью получения дохода или иного полезного эффекта в будущем или настоящем (контроль и регулирование валютного курса государством, средства платежа, конверсия). Все они предполагают покупку/продажу ликвидного актива и возможность получения либо текущей прибыли (убытка), либо отложенной прибыли (убытка) при пересчете по курсу в национальной валюте. Поэтому все цели и операции по покупке/продаже ликвидного актива (валюты, процентной ставки, золота) на валютном рынке в широком смысле признаются автором инвестиционными с позиции получения дохода или иного полезного эффекта.

Наиболее доходными, как и наиболее рискованными, являются спекулятивные операции. Поэтому с позиции главной цели инвестирования - получение высокого дохода (сопряженного с риском) - спекулятивные операции признаются автором инвестиционными в узком смысле. 
Большинство различных подходов определяет инвестирование как совокупность практических действий по реализации инвестиций - сделок купли/продажи [3, 7, 8], а также как реализацию управленческих решений [12] по формированию и использованию финансовых (инвестиционных) ресурсов в процессе выполнения сделок. С такой трактовкой мы можем согласиться.

Наиболее точное определение, на наш взгляд, дал А. Кульман [15. С. 86]: «инвестирование - это операция, посредством которой сбережения трансформируются в средства производства» (имеются в виду реальные инвестиции), или «инвестирование - это процесс преобразования инвестиционных ресурсов во вложения в целях получения доходов в будущем».

Сущностные признаки понятия, отличающие реальные и финансовые инвестиции, приведены в таблице.

Отличительные признаки реальных и финансовых инвестиций *

\begin{tabular}{|c|c|c|c|}
\hline \multirow{2}{*}{$\begin{array}{c}\text { Сущностные при- } \\
\text { знаки }\end{array}$} & \multirow[t]{2}{*}{ Реальные инвестиции } & \multicolumn{2}{|c|}{ Финансовые инвестиции } \\
\hline & & Рынок ЦБ & Валютный рынок \\
\hline Цель & $\begin{array}{lr}\text { «Достижение } & \text { индиви- } \\
\text { дуальных } & \text { целей } \\
\text { инвестора» } & \end{array}$ & $\begin{array}{l}\text { «Получить требуемый ур } \\
\text { ности при более низком } \\
\text { ка» или «достижение ино }\end{array}$ & $\begin{array}{l}\text { овень ожидаемой доход- } \\
\text { уровне ожидаемого рис- } \\
\text { о полезного эффекта» }\end{array}$ \\
\hline $\begin{array}{l}\text { Форма } \\
\text { вания }\end{array}$ & $\begin{array}{l}\text { Капитальные вложения, } \\
\text { вложения в оборотные } \\
\text { средства и нематериаль- } \\
\text { ные активы (лицензии, } \\
\text { патенты, программы и } \\
\text { базы данных для ЭВМ) }\end{array}$ & $\begin{array}{l}\text { Вложения капитала в } \\
\text { инструменты путем сc } \\
\text { ли/продажи }\end{array}$ & $\begin{array}{l}\text { различные финансовые } \\
\text { вершения сделок куп- }\end{array}$ \\
\hline $\begin{array}{l}\text { Объекты инвестиро- } \\
\text { вания: } \quad \text { финансовые } \\
\text { инструменты (активы) } \\
\text { (поставочные и рас- } \\
\text { четные контракты) }\end{array}$ & - & $\begin{array}{l}\text { Депозиты, долевые и } \\
\text { долговые ценные бу- } \\
\text { маги, облигации, акции } \\
\text { и пр., их деривативы }\end{array}$ & $\begin{array}{l}\text { Валюта, процентные } \\
\text { ставки, золото и их } \\
\text { деривативы (все инст- } \\
\text { рументы на наличном и } \\
\text { срочном рынках) }\end{array}$ \\
\hline $\begin{array}{l}\text { Управление } \\
\text { цессом про- } \\
\text { ния }\end{array}$ & $\begin{array}{lc} & + \\
\text { (нет } & \text { спекуляции } \\
\text { хеджирования) }\end{array}$ & + & + \\
\hline Ликвидность актива & - & + & + \\
\hline $\begin{array}{l}\text { Наличие рыночного } \\
\text { риска }\end{array}$ & - & + & + \\
\hline Доход (эффект) & + & + & + \\
\hline
\end{tabular}

* Знак «+» означает наличие признака. Составлено автором.

Основные и оборотные средства, нематериальные активы предприятий не являются финансовыми инструментами, «права получить в будущем финансовый актив не возникает» [12]. Наличие договора в определении финансового инструмента предполагает изменения в финансовых активах, обязательствах и финансовых ресурсах в процессе инвестирования, чего нет в реальных инвестициях. Таким образом, финансовые инвестиции отличаются от реальных формой инвестирования (объект рыночных отношений) и объектом инвестирования - финансовым инструментом. Кроме того, реальные инвестиции не могут быть спекулятивными и хеджируемыми.

Необходимость управления инвестированием актуальна для всех видов, но содержание управления отличается. Финансовое инвестирование сопряжено с высокими рисками в силу изменчивости динамики рынка. Все виды рассмотренных ранее рисков [10], присущие торговым операциям, справедливы для финан- 
сового инвестирования - кредитный, валютный, страновой (политический), операционный (технический).

На основе анализа сущности понятий «международный валютный рынок» и «торговая операция» [10] предложено авторское определение финансовых инвестиций на валютном рынке в широком смысле: «финансовые инвестиции на валютном рынке - это совокупность экономических отношений между участниками рынка по поводу формирования, распределения и использования собственных, заемных и привлеченных финансовых ресурсов, возникающих в прочессе их вложения в форме сделок купли/продажи финансовых инструментов с различным базисным активом (иностранная валюта, прочентная ставка, золото), осуществляемых в условиях риска с ичелью получения дохода или иного полезного эффекта».

Некоторые авторы указывают на особенность инвестиционных операций на валютном рынке, отличающих их от операций на фондовом рынке [2, 18, 19]. Суть рассуждений сводится к следующему.

Инвестиции в фондовый рынок - это вложения финансовых ресурсов посредством операций купли/продажи ценных бумаг, акций, облигаций и прочих активов (или портфеля активов) на длительный срок с целью получения дивидендов (пассивная стратегия). Источник прибыли - «купить активы дешевле, а продать дороже», ожидая увеличения цены актива в долгосрочной перспективе.

Инвестиции на валютном рынке - это вложения финансовых ресурсов посредством торговых операций, осуществляемых с целью извлечения прибыли от разницы цены актива во времени на одном или разных рынках (активная стратегия). Направление торговых операций (покупка/продажа) на валютном рынке не имеет значения, прибыль участника рынка может быть получена как от операции «купля», так и «продажа» как в средне-, так и краткосрочной перспективе.

Однако в настоящее время на фондовом рынке также используются краткосрочные спекулятивные стратегии в биржевом и внебиржевом сегментах. Различия в методах торговли между валютным и фондовым рынками стираются за счет использования электронных методов, в том числе алгоритмической торговли.

Таким образом, считаем, что все торговые операции, осуществляемые на валютном рынке с разными целями, результат которых получение дохода или иного полезного эффекта, - это вложение финансовых ресурсов в ликвидный актив, а источником получения высокого дохода являются спекулятивные инвестиционные операции, хотя они сопряжены с большим риском.

Бенджамин Грэм [16] отделял инвестиции от спекуляций. Инвестиции определял как операции вложения, «основанные на тщательном анализе фактов, перспектив, безопасности вложенных средств и достаточном доходе» [16. Р. 13], все остальное признавал спекуляцией. Привлекательными в плане инвестирования акциями считал те, которые продаются на рынке по цене ниже их внутренней стоимости (ценовой подход к инвестированию) [16. Р. 188], считая, что они в этом случае имеют «запас надежности», полагал ненужным обращать внимание на колебания цены актива во времени (пассивная стратегия «купи - и держи»). Указывал, что «разумный инвестор» относится к инвестиции как к деловому предприятию. Другой подход к инвестированию - «тайминг» [16. Р. 190], основанный на краткосрочных операциях с целью получить прибыль на колебаниях 
цен (активная стратегия), называл спекуляцией. Понимал, что в «ценовом подходе» риск ограничен за счет «запаса надежности», а при спекуляции риск ничем не ограничен. Рекомендовал тактику торговли при «ценовом подходе»: покупать, когда значение цены ниже истинной стоимости акции, а продавать, когда курс превышает истинную стоимость. «Разумный инвестор» покупает на медвежьем рынке по низкой цене, а продает на бычьем рынке по высокой цене. При «тайминге» используется противоположная тактика: рост цены - покупать, снижение - продавать. Б. Грэм считал, что «разумный инвестор» ждет, когда значение цены актива станет ниже истинной стоимости - у него мотив другой, отличный от мотива спекулянта, однако был уверен, что оба - «инвестор» и «спекулянт» - должны анализировать прогнозы состояния фондового рынка.

А.Г. Грязнова и др. [11. С. 900] также отмечают, что «спекуляция от инвестирования отличается уровнем риска», инвестор идет на «проанализированный ограниченный риск», а спекулянт (игрок) идет на неограниченный риск, играя наудачу.

Принципы инвестирования в фондовый рынок Б. Грэм относятся к 4050-м гг. ХХ в. С тех пор многое изменилось в методах торговли. Развитие электронных методов и математического аппарата для прогнозирования динамики рынка и, собственно, для реализации алгоритмической торговли привело к тому, что инвестор использует в своей стратегии научные методы прогнозирования рынка и управления риском, а не полагается на удачу. Специальные дополнительные инструменты для ограничения риска - защитные ордера в торговой стратегии - позволяют ограничить текущий риск операции.

Совершенствование законодательства России, регулирующего внебиржевой сегмент валютного рынка, привело к увеличению в 2 раза оборотов за 2014 г. [17]. Российское законодательство (с декабря 2014 г.) относит операции на внебиржевом межбанковском валютном рынке (российский сегмент рынка называется «Форекс») к рынку ценных бумаг и регулирует отношения между профессиональными участниками рынка (дилерами/брокерами) и клиентами. Сделки купли/продажи расчетными контрактами (контракты на разницу) не признаются сделками «пари», как раньше, и подлежат судебной защите (ст. 11 Ф3 РФ) [17].

Многие исследователи отмечают $[8,12,18,19]$, что спекуляция имеет свои достоинства: стабилизирует цены на рынке, приближая рынок к равновесию, осуществляет перенос рисков хеджеров на спекулянтов - и также относят спекулятивные операции на валютном рынке к инвестиционным.

Таким образом, мнение автора статьи состоит в следующем: все цели и операции по покупке/продаже ликвидного актива (валюты, процентной ставки, золота) на валютном рынке в широком смысле признаются инвестиционными с позиции получения дохода или иного полезного эффекта. Наиболее доходными, как и наиболее рискованными, являются спекулятивные операции. Поэтому с позиции главной цели инвестирования - получения высокого дохода (сопряженного с большим риском) - спекулятивные операции признаются автором инвестиционными в узком смысле.

Высокий удельный вес спекулятивных операций свидетельствует о необходимости прогнозирования динамики рынка и управления капиталом в инвестиционной стратегии. Большая часть торговых операций на валютном рынке осу- 
ществляется методом алгоритмической торговли $-74 \%$ среднедневного оборота международного валютного рынка [20].

В этом контексте направление дальнейших исследований - уточнение сущности и содержания категории «финансовый механизм инвестирования на основе алгоритмической торговли на международном валютном рынке», в соответствии с данным определением финансовых инвестиций, представляется актуальным на современном этапе развития рынка.

Предложенное автором определение финансовых инвестиций, в отличие от известных, все торговые операции на международном валютном рынке признает инвестиционными и объясняет базовые элементы структуры финансового механизма инвестирования, в частности включение технического инструментария выполнения операций - механической торговой системы, как субъекта управления капиталом и риском.

\section{Лumepamypa}

1. Литинский Д.С. Статистическое прогнозирование для построения эффективных торговых стратегий на валютном рынке: автореф. дис. ... канд. экон. наук. М., 2003. 23 с.

2. Салин В.Н. Биржевая статистика: учеб. пособие/ В.Н. Салин, И.В. Добашина. М.: Финансы и статистика, $2003.176 \mathrm{c}$.

3. Межов И.С., Межов С.И. Инвестиции: оценка эффективности и принятие решений. Новосибирск: Изд-во НГТУ, 2011. 380 с.

4. Райзберг Б.А., Лозовский Л.Ш. Словарь современных экономических терминов. 4-е изд. М.: Айрис-пресс, 2008. 480 c.

5. Чалдаева Л.А. Рынок ценных бумаг: учеб. для бакалавров/ Л.А. Чалдаева, А.А. Килячков. 3-е изд., перераб. и доп. М.: Юрайт, 2012. 857 с.

6. Корчагин Ю.А., Маличенко И.П. Инвестиции и инвестиционный анализ: учеб. Ростов н/Д: Феникс, 2010. 601 с.

7. Финансы, денежное обращение и кредит: учеб. для бакалавров / Л.А. Чалдаева [и др.]. $2-$ е изд., испр. и доп. М.: Юрайт, 2013. 542 с.

8. Инвестиции: учеб. пособие / М.В. Чиненов [и др.]. 2-е изд., перераб. и доп. М.: Кнорус, 2008. $368 \mathrm{c}$.

9. Довбенко М.В., Осик Ю.И. Современные экономические теории в трудах нобелиантов: учеб. пособие. М.: Изд-во Академия естествознания, 2011. URL: http:// www. monographies.ru/129 (дата обращения: 01.03.2015).

10. Крюков П.А. Определение торговой операции на валютном рынке Forex // Вестн. Том. гос. ун-та. Экономика. 2014. № 2(26). С. 99-108.

11. Финансово-кредитный энциклопедический словарь / А.Г. Грязнова [и др.]. М.: Финансы и статистика, 2004. $1168 \mathrm{c}$.

12. Бланк И.А. Основы инвестиционного менеджмента: в 2 т. 3-е изд., стер. М.: Омега-Л, 2008. T. $1.660 \mathrm{c}$

13. Бланк И.А. Основы инвестиционного менеджмента: в 2 т. 3-е изд., стер. М.: Омега-Л, 2008. T. 2. $560 \mathrm{c}$.

14. Иванов А.П. Финансовые инвестиции на рынке ценных бумаг. 3-е изд., перераб. и доп. М.: ИТК «Дашков и $\mathrm{K}^{0} », 2008.480$ c.

15. Кульман А. Экономические механизмы: пер. с фр./ общ. ред. Н.И. Хрусталевой. М.: А/O Изд. группа «Прогресс»: «Универс», 1993. 192 с.

16. Graham Benjamin. The intelligent investor. A book of Practical counsel. Updated with new commentary by Jason Zweig: HarperCollins Publishers, Inc., 2003. 627 p.

17. Федеральный закон от 29 декабря 2014 года № 460-Ф3 «О внесении изменений в отдельные законодательные акты Российской Федерации» [Электронный ресурс] // КонсультантПлюс. Электрон. дан. КонсультантПлюс, 2014. URL: http://base.consultant.ru/cons/cgi/online.cgi? req=doc;base=LAW;n=172869 (дата обращения: 09.01.2015). 
18. Аненкова Л.А. Совершенствование финансового механизма иммунизации инвестиционной стратегии дилинговых операций на международном валютном рынке (на материалах валютного рынка Forex): автореф. дис. ... канд. экон. наук. Ростов н/Д, 2010. 25 с.

19. Федоров A.B. Организация и финансовые инструменты инвестиционно-оверлейной деятельности на валютном рынке: дис. ... канд. экон. наук. Владивосток, 2005. 169 с.

20. Опрос Центрального банка трехлетнего периода («Triennial Central Bank Survey 2013», декабрь 2013 г.) [Электронный ресурс] / Банк международных расчетов. Электрон. дан. BIS, 2013. URL: www.bis.org (дата обращения: 02.02.2014).

\section{P.A. Kryukov}

Department of Management Accounting and Analysis, Institute of Economics and Management, Kuzbass State Technical University named after T.F.Gorbachev, Kemerovo, Russia E-mail: kpa.2008@mail.ru

THE NOTION OF FINANCIAL INVESTMENTS IN THE FOREIGN EXCHANGE MARKET

Keywords: Financial investment; Speculation; Currency market; Foreign exchange market; Financial asset.

Currently, the term "financial investment" has no clear-cut interpretation for the currency market in economic literature. There is no consensus as to whether the investment-governmental speculation, especially on the OTC market? Are all the trading operations carried out with different objectives and investment?

In scientific literature, there are three approaches to defining "financial investments":

1) financial investment is an investment of investors' private or borrowed funds in financial instruments (financial assets and liabilities) for a specific purpose, which is usually "to get the desired level of expected returns with lower expected risk" or "to achieve another useful effect";

2) financial investment is an investment by means of the transactions purchase/sale of financial instruments in the investment market, including the foreign exchange market;

3) financial investments as an economic category and as a process can also mean "cumulative investment movement, different forms and levels", which is implemented through the a mechanism inherent in the investment market.

All the approaches are focused on a particular aspect. We studied the essential features of financial investment companies. It was found that six features are more attributed to the financial investment in the foreign exchange market. These are liquid assets, presence of a risk, a source of income (profit), the stated object of market relations (the object of purchase/sale), facility management, the active form of involvement of capital in economic process. The author proposed to add the following characteristics to the list: target and underlying asset as well as the form and object of investment, the need for management of the investment process.

Based on the analysis of the essence of the concepts "international foreign exchange market" and "trading" carried out by the author in earlier works, a definition of financial investment in the foreign exchange market in the broadest sense was formulated. According to this definition, financial investment in the currency market is a set economic relations among market participants connected with the formation, distribution and use of private and borrowed financial resources arising in the course of their investment in the form of the transactions of purchase/sale of financial instruments with different underlying assets (foreign currency, interest rate gold), implemented under a minute figure to generate an income or another benefit.

Thus, all trading transactions on the foreign exchange market with different targets, the result of which are an income or another useful benefit shall be considered as an investment of financial resources in liquid assets.

\section{References}

1. Litinskiy D.S. Statisticheskoye prognozirovaniye dlya postroyeniya effektivnykh torgovykh strategiy na valyutnom rynke: Avtoref. dis. kand. ekon. nauk [Statistical forecasting for building effective trading strategies in the foreign exchange market. Synopsis of PhD in Econ. Diss.]. Moscow, 2003. 23 p. 
2. Salin V.N., Dobashina I.V. Birzhevaya statistika [Exchange statistics]. Moscow, Finansy i statistika Publ., 2003.176 p.

3. Mezhov I.S., Mezhov S.I. Investitsii: otsenka effektivnosti i prinyatiye resheniy [Investments: performance evaluation and decision-making]. Novosibirsk, Novosibirsk State Technical University Publ., 2011. 380 p.

4. Rayzberg B.A., Lozovskiy L.Sh. Slovar' sovremennykh ekonomicheskikh ter-minov [Glossary of modern economic terms], $4^{\text {th }}$ edn. Moscow, Ayris-press Publ., 2008. 480 p.

5. Chaldayeva L.A., Kilyachkov A.A. Rynok tsennykh bumag [Securities market], 3d edn. Moscow, Yurayt Publ., 2012. 857 p.

6. Korchagin Yu.A., Malichenko I.P. Investitsii $i$ investitsionnyy analiz [Investments and investment analysis]. Rostov-on-Don, Feniks Publ., 2010. 601 p.

7. Chaldayeva L.A., et al. Finansy, denezhnoye obrashcheniye i kredit [Finance, monetary circulation and credit]. Moscow, Yurayt Publ., 2013. 542 p.

8. Chinenov M.V., Chernousenko A.I., Zozulya V.I. Investitsii [Investments]. Moscow, Knorus Publ., 2008. 368 p.

9. Dovbenko M.V., Osik Yu.I. Sovremennyye ekonomicheskiye teorii v trudakh nobeliantov. Moscow, Akademiya estestvoznaniya Publ., 2011. Available at: http://www.monographies.ru/129 (accessed 01 March 2015).

10. Kryukov P.A. Opredeleniye torgovoy operatsii na valyutnom rynke Forex [The definition of trading operations on the Forex market]. Vestnik Tomskogo gosudarstvennogo universiteta. Ekonomika - Tomsk State University Journal of Economics, 2014, no. 2(26), pp. $99-108$

11. Gryaznov A.G., et al. Finansovo-kreditnyy entsiklopedicheskiy slovar' [Financial and Credit Encyclopedic Dictionary]. Moscow, Finansy i statistika Publ., 2004. 1168 p.

12. Blank I.A. Osnovy investitsionnogo menedzhmenta [Fundamentals of investment management]. Moscow, Omega-L Publ., 2008. 660 p.

13. Blank I.A. Osnovy investitsionnogo menedzhmenta [Fundamentals of investment management]. Moscow, Omega-L Publ., 2008. 560 p.

14. Ivanov A.P. Finansovyye investitsii na rynke tsennykh bumag [Financial investments in the securities market]. Moscow, Dashkov i $\mathrm{K}^{\mathrm{o}}$ Publ., 2008. 480 p.

15. Kul'man A. Ekonomicheskiye mekhanizmy [Economic mechanisms]. Moscow, Progress Publ., Univers Publ., 1993. 192 p.

16. Benjamin Graham. The Intelligent Investor. A Book of Practical Counsel. Updated with new commentary by Jason Zweig, HarperCollins Publishers, Inc., 2003. 627 p.

17. RF Federal Law "On the Introduction of Amendments to Certain Legislative Acts of the Russian Federation" of December 29, 2014 N 460-FZ. Available at: http://base.consultant.ru/cons/ cgi/ online.cgi?req=doc;base=LAW;n=172869 (accessed 01 September 2015). (In Russian).

18. Anenkova L.A. Sovershenstvovaniye finansovogo mekhanizma immunizatsii investitsionnoy strategii dilingovykh operatsiy na mezhdunarodnom valyutnom rynke (na materialakh valyutnogo rynka Forex): avtoref. dis. kand. ekon. nauk. Rostov-on-Don, 2010. 25 p.

19. Fedorov A.V. Organizatsiya $i$ finansovyye instrumenty investitsionno-overleynoy deyatel'nosti na valyutnom rynke: dis. kand. ekon. nauk. Vladivostok, 2005. 169 p.

20. Bank for International Settlements. A Survey of the Central Bank's Three-Year Period ("Triennial Central Bank Survey 2013", December 2013). Available at: www.bis.org (accessed 02 February 2014).

\section{For referencing:}

Kryukov P.A. Ponyatiye finansovykh investitsiy na mezhdunarodnom valyutnom rynke [The notion of financial investments in the foreign exchange market]. Vestnik Tomskogo gosudarstvennogo universiteta. Ekonomika - Tomsk State University Journal of Economics, 2016, no. 3 (35), pp. 124134. 